\title{
Cognitive-linguistic deficit and speech intelligibility in chronic progressive multiple sclerosis
}

Catherine Mackenzie

Department of Educational and Professional Studies, University of Strathclyde, Glasgow

Jan Green

Department of Speech and Language Therapy, Forth Valley NHS Board

Correspondence to:

Professor C Mackenzie

Department of Educational and Professional Studies

University of Strathclyde

Southbrae Drive

Glasgow G13 1PP

01419503454

c.mackenzie@strath.ac.uk

Keywords: multiple sclerosis speech intelligibility cognitive language 


\begin{abstract}
Background

Multiple sclerosis (MS) is a disabling neurological disease with varied symptoms, including dysarthria and cognitive and linguistic impairments. Association between dysarthria and cognitive-linguistic deficit has not been explored in clinical MS studies.
\end{abstract}

\title{
Aims
}

In MS patients with chronic progressive (CP) MS, the study aimed to investigate the presence and nature of cognitive-linguistic deficit, association between levels of cognitive-linguistic ability and speech intelligibility and of both of these with functional disability and time since onset (TSO) of MS symptoms.

\section{Methods and Procedures}

The Arizona Battery for Communication Disorders of Dementia (ABCD) (Bayles and Tomoeda 1993), The Assessment of Intelligibility of Dysarthric Speech (AIDS) Sentence Intelligibility Task (Yorkston and Beukelman 1984) and the Modified Barthel Activities of Daily Living Index (MBADLI) (Shah1998) were administered to 24 CP MS participants with dysarthria. 24 non neurologically impaired participants, matched for gender, age and education, formed a control group.

Outcome and Results

For MS participants, linear regression analysis showed a strong association between $\mathrm{ABCD}$ and AIDS $($ Beta $=.89, \mathrm{p}=0.005)$, no association between $\mathrm{ABCD}$ and either 
MBADLI or TSO, a strong association between AIDS and MBADLI $($ Beta $=0.60, p=$ $.001)$, and a trend towards association between AIDS and TSO $($ Beta $=-.29, \mathrm{p}=0.08)$. Correlations between the four included $\mathrm{ABCD}$ construct scores and between these and the total $\mathrm{ABCD}$ score were significant $(\mathrm{r}>.60, \mathrm{p}<.01)$.

For each of the 15 included $\mathrm{ABCD}$ measures and for the four construct scores and the overall $\mathrm{ABCD}$ score, $\mathrm{MS}$ and control group performances were significantly different ( $\mathrm{p}$ $<.01)$ and effect sizes were large $(\mathrm{d}>.80)$.

\section{Conclusions and clinical implications}

The results revealed a strong association between dysarthria, as measured by connected speech intelligibility testing, and cognitive-linguistic deficit, in people with CP type MS. While some of the impairments which are associated with MS, including motor speech disorder, may influence performance on the $\mathrm{ABCD}$, the data support the conclusion that marked cognitive-linguistic deficit is present in CP type MS patients with dysarthria. Deterioration was global, rather than being indicative of a construct specific deficit, and encompassed language, both expression and comprehension. Episodic memory and linguistic expression were especially affected.

Speech and language therapists who work with dysarthric patients with CP MS should monitor cognitive-linguistic impairment. Awareness of this may influence assessment, intervention and management, including the information and advice given to patients and their relatives. 


\section{Introduction}

Multiple sclerosis (MS) usually begins in the 20-40 age group. It is a degenerative disease of unknown aetiology, with an autoimmune component, in which selective demyelination produces lesions throughout the white matter of the brain and spinal cord, resulting in a range of neurological deficits, including communication and communication-related problems (Gilroy 2000). The course is unpredictable, though clinical subgroups are identified, the main types being chronic progressive $(\mathrm{CP})$ and relapsing-remitting $(\mathrm{RR})$, which may develop into the CP type. $70 \%$ of patients with MS pass through a RR stage (Lindsay and Bone 2004). In a minority of patients the course is benign, with a low level of disability 10 years after onset (Lindsay and Bone 2004).

Motor speech problems are thought to be present in around $40-50 \%$ of people with MS. The type of dysarthria varies, reflecting the individual neurological profile, but ataxic (cerebellar) and spastic (upper motor neurone) components are most common (Duffy 2005). The perceptual, acoustic and physiological features of dysarthria, and related intervention, have been the subject of several publications (see Murdoch and Theodoros 2000). Dysphagia has a prevalence of $34 \%$ in MS (Calcagno et al. 2002).

Whether language difficulties are commonly associated with MS has been debated. There has been some assumption that as the neuropathology of MS is largely subcortical, language function should not be affected. Some authors have reported no significant 
language differences between control and MS participants, but it has been suggested this may be attributable to limited test sensitivity (Murdoch and Lethlean 2000), the aspects of language selected for assessment or the stage in disease (Amato et al. 1995), or the predominant type of disease in the sampled group (Beatty et al. 1989). People with MS commonly perceive themselves as having language difficulties which impact on their quality of life (Klugman and Rose 2002). Arnott et al. (1997) found the narratives of an MS group were less informative and contained more ambiguous and incorrect information than those of a control group. Murdoch and Lethlean (2000), who conducted comprehensive assessment of language skills in MS, found performance significantly below a control group on a variety of language measures, including naming, word definition, word fluency, sentence repetition, verbal explanation, verbal reasoning and high level comprehension, such as that requiring logico-grammatical operations and interpretation of absurdities, ambiguities and metaphor. No cases of classical aphasia were found. Different performance subgroups were identified, based on severity of language deficit, including a group comprising over $50 \%$ of the sample with essentially normal language abilities.

Varied explanations have been forwarded for low language test scores in MS, including phonatory, visual or oculomotor impairment (Jennekens-Schinkel et al. 1990). Murdoch and Lethlean (2000) noted the interdependence of language and cognitive functions within discriminating language tasks. Kujala et al. (1996), finding language to be unimpaired in MS patients who had preserved cognitive abilities, but impaired in those with cognitive decline, interpreted the language loss as cognitive in origin, noting that 
language functions were vulnerable in MS, even in those whose cognitive loss was mild. Cognitive deficit is reported in around 43\% of adults with MS (Rao et al. 1991), may be present at an early stage in the disease (Amato et al 1995), and has been observed in children and adolescents (MacAllister et al. 2005). At times, cognitive difficulties have been diagnosed as subcortical dementia (Rao et al. 1991) or combined cortical and subcortical dementia (Beatty et al.1989, Friend et al. 1999).

The literature on cognitive, including language, skills in MS is often conflicting as to the presence and severity of deficits, and association between deficits and disease variables, such as duration and type of MS, and physical and functional disabilities. From a metaanalysis of 34 relevant studies published between 1983 and 1997, Zakzanis (2000) confirmed that a large proportion of the MS population is impaired on standard neuropsychological tests, including measures of general intelligence, verbal skills, attention/concentration, memory, cognitive flexibility and abstraction. Differing patterns and extent of deficit were found in patients with RR and CP MS, leading to the conclusion that failure to distinguish these two types may account for absence of significant differences between MS and control participants in some studies. Two language studies (Heaton et al. 1985, Lethlean and Murdoch 1994), not included in the Zakzanis (2000) meta-analysis, found more pronounced deficits in the CP than in the RR type of MS. Greater lesion load or longer illness duration in CP patients (Beatty et al. 1989) may contribute to this finding. Amato et al. (1995) found deficits present at four year follow up of a mainly RR group, which had not been observed at earlier assessment. However other authors have found no correlation between cognitive -linguistic 
impairment and illness duration (Rao et al. 1991, Lethlean and Murdoch 2000).

Association with level of physical disability has been noted (Rao et al. 1991, Ron et al. 1991) but this too is not a consistent finding (Amato et al. 1995, Lethlean and Murdoch, 2000).

Where people with MS are referred to speech and language therapy (SLT), this is likely to be because of the presence of dysphagia or dysarthria. Early intervention is advocated for dysarthria in MS, including for those whose motor speech involvement is at a preclinical stage (Theodoros and Ward 2000). According to Duffy (2005), dysarthria severity in MS is generally related to overall severity of neurological deficit, including physical and cognitive deficits. A relationship between self-reported speech severity and problems of thinking, reading and writing was found by Yorkston et al. (2003). Association between dysarthria and cognitive-linguistic deficit has not been explored in clinical MS studies, and those with impaired speech have sometimes been excluded from studies on cognition and language. Management and response to dysarthria intervention may be negatively affected by the presence of cognitive-linguistic deficit. Even discrete cognitive-linguistic problems may affect overall functional capacity, including in professional and social life (Laakso et al. 2000; Yorkston et al. 2001). Routine assessment of language in MS has been advocated (Friend et al.1995, Kujala et al. 1996). Our clinical and research experience suggests that language is not typically assessed in dysarthric MS patients in the UK. If language deficit is present, as well as potential influences on the management of speech and swallowing difficulties, and on prognosis, 
this may be a further target for intervention. The relationship between dysarthria severity and cognitive-linguistic ability is thus worthy of investigation.

Where language has been assessed in MS, this has generally been in the context of broad neuropsychological measurement, usually using a series of individual tests, which do not provide a comprehensive profile of language functions. The Arizona Battery for Communication Disorders of Dementia (ABCD) (Bayles and Tomoeda 1993) is a standardised battery which permits assessment of both language and cognitive skills. It can be administered either in its entirety or by use of selected subtests, and response requirements allow for its use with non-ambulatory patients (Bayles and Tomoeda1993). Wallace and Holmes (1993) reported performance differences in four MS patients and an age matched control group in some components of the $\mathrm{ABCD}$, leading the authors to suggest that the $\mathrm{ABCD}$ may be a sensitive measure of subtle linguistic impairment in MS. Armstrong et al. (1996), in a comparison between UK and US performance, reported excellent correspondence between US and UK scores, using a few alterations appropriate to the UK, and concluded the ABCD could be used with confidence in the UK. The $\mathrm{ABCD}$ authors provide normative data for old (mean age 70) and young (mean age 20) control groups. For use in UK research with MS participants, a suitably matched control group is desirable.

For a group of CP type MS patients, under the care of a speech and language therapist, the study aimed to determine: 
a) Association between cognitive-linguistic ability and a) level of speech intelligibility, b) functional disability, and c) time since onset of MS symptoms.

b) Association between speech intelligibility and a) functional disability, and b) time since onset of MS symptoms.

c) The presence and nature of cognitive-linguistic deficit.

\section{Methods and procedures}

\section{Participants}

\section{Multiple sclerosis}

Participants, with a dysarthria diagnosis, who had been in contact with SLT, not more than six months previously, were recruited via four SLT departments. Supervising therapists referred to the study patients from their caseloads who fulfilled the criteria of a clinically definite diagnosis of CP type of MS, uncomplicated by other neurological disorder, previous learning disability or speech or language disorder, and in the referring therapist's opinion, levels of stamina, hearing and vision sufficient for participation in speech and cognitive-linguistic assessment. Participant MS1 had a history of seizures prior to diagnosis of MS, but this was considered by the neurologist as an early presentation of MS (Gilroy 2000).

24 people were recruited. There were 16 females and eight males. Age range was 23 to 73 years (mean 46.58, SD 12.17). Time since onset of symptoms ranged from two to 34 years (mean 12.79, SD 8.48). Reported education ranged from nine to 18 years (mean 
13.25, SD 2.82). Demographically the participant sample was comparable to that of the Zakzanis (2000) analysis of 351 patients with CP MS, in which the typical patient was female, 45 years old, with 14 years of education and illness duration of 13 years. 19 participants lived at home, and five lived in residential care facilities. At the time of assessment, three were employed, in each case being either self-employed or working for a family member.

\section{Control}

24 control participants, without known neurological or psychiatric impairment, were recruited via personal contacts, to match the MS group members, in respect of gender, age and education. Age was $+/$ - four years and education $+/$ - two years of each matched MS participant. Age range was 21 to 76 (mean 46.79, SD 12.45). Reported education ranged from 11 to 19 years (mean 13.71 SD 2.48). There was no significant difference between the MS and control groups in age or education (age: $t(46)=-.06$, education: $t$ $(46)=-.60$, both n.s.). Environment was not matched to MS participants, in view of the difficulty of sourcing appropriate middle aged people without neurological or learning disability within a care facility. All lived at home.

All participants were native to, or long-term residents of, west-central Scotland and English was their first language.

Participant data for MS and control groups are given in Table 1. 
Assessment

1. Cognitive-linguistic ability: Arizona Battery for Communication Disorders of Dementia (ABCD) (Bayles and Tomoeda 1993). The tests for four of the five constructs were used (Mental Status. Episodic Memory, Linguistic Expression, Linguistic Comprehension). Motor impairments precluded completion of the Visuospatial Construction construct, which comprises drawing and figure copying, in the first four participants who were assessed, and a decision was taken to omit these. 15 of the ABCD's 17 measures were thus administered: mental status (MSt), story retelling - immediate (SRI), following commands (FC), comparative questions (CQ), word learning - free recall (WLFR), word learning total recall (WLTR), word learning -recognition (WLR), repetition (R), object description (OD), reading comprehension - word $(\mathrm{RCW})$, reading comprehension - sentence (RCS), generative naming (GN), confrontation naming $(\mathrm{CN})$, concept definition (CD), and story retelling - delayed (SRD) . UK amendments (Armstrong et al. 1996) were incorporated (e.g.Who is the President of the USA? was replaced by Who is the Prime Minister?). Test data were available for all participants.

2. Sentence intelligibility: Assessment of Intelligibility of Dysarthric Speech (AIDS) (Yorkston and Beukelman 1984). As an overall index of dysarthria severity, sentence intelligibility assessment has face validity and is useful for the rankordering of dysarthric speakers (Yorkston and Beukelman 1984). Test data were 
available for all MS and 16 control participants. Age and education did not differ between these and the 24 MS participants (age: $\mathrm{t}(38)=-.038$; education: $\mathrm{t}(38)=$ -.785 , both n.s.).

3. Functional disability rating: Modified Barthel Activities of Daily Living Index (MBADLI) (Shah1998). 10 questions cover ability to perform activities of daily living such as feeding, grooming, and toilet use. The maximum score of 20 indicates physical independence, though not necessarily absence of impairment or social independence, scores of 15-19 are associated with mild, 10-14 with moderate, 5-9 with severe, and 0-4 with very severe disability and dependence. Only MS participants were assessed.

\section{Administration and scoring}

Assessment was carried out in a quiet environment, at a location convenient for the participant: home, hospital, care facility, or university. ABCD and AIDS were administered with a short break between. Opportunities for additional breaks were provided. Two research speech and language therapist assessors were involved, with administration and scoring monitored by a third researcher. Adequacy of auditory and visual acuity was checked informally by asking participants if they could hear the assessor and clearly see the materials as presented. Care was taken to position materials optimally for the individual, to ensure that all stimuli could be seen. All participants passed the $\mathrm{ABCD}$ screening tests, indicating sufficiency of hearing and vision for test performance. For MS participants MBADLI was then completed independently, or with the assistance of a caregiver. Total assessment time averaged one hour and did not exceed 
90 minutes. Sessions were recorded on audio cassette, with external microphone, placed approximately $20 \mathrm{~cm}$ from the participant's face.

\begin{abstract}
ABCD: In subtests which required a spoken or gestural response, all recognizable approximations to target were credited. In accordance with test instructions, subtest raw scores were converted to summary scale scores (1-5) and construct scores (1-5) were calculated from the relevant summary scale scores (4 construct scores in this investigation: Mental Status (MScon), Episodic Memory (EMcon), Linguistic Expression (LEcon), and Linguistic Comprehension (LCcon). An overall performance score $(\mathrm{ABCDOP})$ was derived from the sum of the construct scores $(4-20$ in this investigation).
\end{abstract}

Several ABCD measures included spoken responses. From the audio recordings, $20 \%$ of these data were scored independently by a second rater and $20 \%$ were rescored blind by the original scorer, several weeks later. Some of the subtests require only a yes or no response so permit objectivity in scoring. In others, judgement is required as to whether a response should be credited. While the test manual provides guidance, inevitably there are instances where consistency between raters is not total, or where a rater makes a different judgement when reanalysing the data. For both inter-rater and intra-rater measurements, raw scores did not differ by more than one point, with the exception of $\mathrm{CD}$, where both in inter-rater and intra-rater checks there was one instance of a 3 raw point discrepancy (48/60 v. 51/60 and 51/60 v. 54/60). 
AIDS: In accordance with AIDS instructions, for each participant 22 sentences, graded in length from five to 15 words, were selected from the large available pool, using the AIDS random number table. Each sentence was presented in written form and read aloud by the researcher, followed by production by the participant. In order to minimise effects of any visual difficulties in the MS participant group, font size was increased from 12 to 20 . The audio recordings were digitized via a USB interface using Soundtrack Pro set to 16bit and 44.1kHz sample rate and backed up to DVD. Once digitized, the sequences were transferred to ProTools where they were edited into the identified clips (assessor's stimulus utterances and other extraneous speech removed) and normalised to maximize processing information. The individual clips were then transferred back to Soundtrack Pro where they were processed on an individual basis to remove any extraneous rumples and low frequency artefacts. Clips were again normalised, then a 'clean' sample of noise was taken and applied, using various threshold points to maximise audio speech frequencies and clarity. Clips were then transferred to CD Mastering software 'Roxio Jam' for normalisation again before burning to CD_A. Following the recommended procedure (Yorkston and Beukelman 1984), two judges, with good hearing acuity, independently transcribed all data as fully as possible, listening to each sentence a maximum of two times. Guessing was encouraged where necessary. Each word transcribed correctly was assigned a score of one and incorrect or omitted words scored 0 , thus providing a maximum score of 220. Transcriptions were compared by one of the researchers. The participant's score was calculated as the number of words consistent with the stimulus. There was $98 \%$ agreement between listeners as to whether words 
corresponded to the stimulus. As expected, no control participant score was below $99 \%$ intelligibility.

\section{Statistical analysis}

Data were analysed using SPSS, version 14. For the MS group, associations between ABCDOP and AIDS, MBADLI, and time since onset of MS symptoms (TSO) and similarly between AIDS and MBADLI and TSO were measured by regression analysis. Pearson tests were used for correlations between $\mathrm{ABCD}$ construct scores and with the overall performance score (ABCDOP).Comparisons between MS and control group performance on the $\mathrm{ABCD}$ measures were by $\mathrm{t}$ tests for independent samples. Effect sizes were calculated using Cohen's d, with $0.2=$ small, $0.5=$ moderate and $0.8=$ large effect sizes (Cohen 1988).

\section{Results}

Associations amongst variables in MS

The MS participant group varied in intelligibility as represented by AIDS scores (14 217), cognitive linguistic skills, as represented by ABCDOP scores (7.95 -19.60), disability, as represented by MBADLI scores (0-20) and time since symptom onset (2-34 years). Details are given in Table 2.

Table 2 about here 
Linear regression analysis was used to examine the association between the dependent variable, $\mathrm{ABCDOP}$, and the three independent variables, AIDS, MBADLI, and TSO. Correlations between AIDS and MBADLI, AIDS and TSO, and MBADLI and TSO were respectively $-0.64,0.37$ and 0.16 , so indicating the lack of collinearity between the independent variables required for regression analysis (Kerr et al. 2002). $\mathrm{F}=4.99, \mathrm{p}=$ 0.01 . Adjusted R square $=0.34$. Thus for $\mathrm{ABCD}$ scores $34 \%$ of the variance was attributable to AIDS, MBADLI, and TSO. Standardised coefficients: AIDS: Beta $=.89$, $\mathrm{p}=0.005$, MBADL: Beta $=-.41$, n.s., TSO: Beta $=-.03$, n.s. Thus correlation between $\mathrm{ABCD}$ and $\mathrm{AIDS}$ scores was strong, and there was no demonstrated association between ABCD and either MBADLI or TSO. Partialled correlation between ABCD and AIDS scores, removing the effects of MBADLI and TSO was 0.58 . The addition of age and years of education to the analysis had little effect (Adjusted R square= 0.39).

Linear regression analysis was used to examine the association between the dependent variable, AIDS, and the two independent variables, MBADLI and TSO. Correlation between MBADLI and TSO was 0.56 , so indicating the lack of collinearity between the independent variables required for regression analysis (Kerr et al. 2002). $\mathrm{F}=18.79, \mathrm{p}<$ 0.001 . Adjusted R square $=0.61$. Thus for AIDS scores $61 \%$ of the variance was attributable to MBADLI, and TSO. Standardised coefficients: MBADLI: Beta $=0.60, p$ $<.001$, TSO Beta $=-.29, \mathrm{p}=0.08$. Thus there was a strong correlation between AIDS and MBADLI scores, and a trend towards association between AIDS and TSO. Partialled correlation between AIDS and MBADLI scores, removing the effect of TSO was 0.64. Partialled correlation between AIDS and TSO, removing the effect of 
MBADLI score was -0.37 . The addition of age and years of education to the analysis had little effect (Adjusted R square=0.67).

For the MS group, correlations between ABCD construct scores (MScon, EMcon, LEcon and LCcon) were significant at $\mathrm{p}<.001$. The lowest inter -construct correlations were between LCcon and MScon (.62) and LCcon and EMcon (.66) and the highest were between MScon and LEcon (.87) and EMcon and MScon (.79). Correlations between ABCDOP and individual construct scores were all very high: MScon: .91, EMcon: .86, LEcon: .95 and LCcon: .87.

Cognitive-linguistic performance in MS and control groups MS and control group performance was compared by $\mathrm{t}$ tests for independent samples and effect sizes (Cohen's d) were calculated to permit comparison of results across tests. For each of the four ABCD constructs and for the total from the 4 constructs (ABCDOP), the MS group scores were significant lower than the control group and effect sizes were all large $(\mathrm{d}=-1.61--2.33)$ from greatest to least EMcon, LEcon, MScon, LCcon (see Figure 1 and Table 3).

Figure 1 about here

Table 3 about here

Examination of the raw scores for the 15 individual ABCD measures showed a consistent pattern of significantly lower scores in the MS group and large effect sizes $(\mathrm{d}=-2.46-$ - 
0.83) (see Table 4). In addition there was a significant difference between MS scores on SRI and SRD $(t(23)=4.65, p<.001)$, but not for the control group $(t(23)=-.86$, n.s. $)$.

\author{
Table 4 about here
}




\section{Discussion}

\section{Associations amongst variables in MS}

The results of the investigation confirm a strong association between dysarthria, as measured by connected speech intelligibility testing, and cognitive-linguistic deficit, in people with CP type MS. Intelligibility assessment examines the extent to which a speaker makes himself/herself understood, and is thus a useful indicator of dysarthria severity (Yorkston and Beukelman 1984). Participants with good intelligibility were likely to also perform well on the cognitive-linguistic assessment, while those with low intelligibility tended to perform poorly. The findings suggest that many of the CP MS patients on a typical SLT caseload, who have dysarthria, will have some impairment of cognitive-linguistic function. This may affect capacity to benefit from dysarthria and dysphagia management in which ability to understand explanation, follow, retain and apply instruction and advice, implement facilitative strategies and monitor performance are all relevant. Little information exists as to the outcome of SLT intervention with the MS population. The results of this investigation suggest that level of cognitive-linguistic ability should be controlled in future dysarthria intervention efficacy research, given its potential to influence response to treatment (Helm-Estabrooks 2002).

Several other variables were considered for their potential influence on cognitivelinguistic performance. As with the research of Rao et al. (1991) and Lethlean and Murdoch (2000), time since MS symptom onset was not relevant, nor was physical disability, consistent with the findings of Amato et al. (1995) and Lethlean and Murdoch 
(2000). Physical disability however was associated with intelligibility level. This finding accords with Duffy's (2005) claim that in MS dysarthria, severity is generally associated with physical deficit and Yorkston et al' s (2003) finding of a very strong relationship between self reported severities of MS and speech problems. Though short of statistical significance, the trend to association between time since MS symptom onset and intelligibility level should be noted. Similarly a trend towards longer duration of symptoms in MS patients who had self reported moderate to severe speech change was observed by Yorkston et al. (2003). The proportion of the intelligibility score variance which was explained by physical disability and time since onset was very high (61\%). As with cognitive-linguistic ability, neither age nor education influenced intelligibility score.

\section{Cognitive-linguistic performance in MS}

The performance data on $\mathrm{ABCD}$ provides additional substantiation for the finding of previous researchers, that people with MS may show both cognitive and language deficits. There was a consistent depletion of performance, relative to the control group, both across the MS test raw scores, and also when overall $\mathrm{ABCD}$ and individual construct scores were examined. Correlations between the scores for the four constructs were all high, as were correlations between the overall $\mathrm{ABCD}$ score and individual construct scores. This generalised pattern suggests a global deterioration of skills, rather than being indicative of a construct specific deficit, and encompasses language, both expression and comprehension. Some individual participants performed as well as the control group, but in no measure was there indication of preservation of ability across the MS group. 


\section{Performance influencing factors}

Some of the impairments which are associated with MS may influence performance on cognitive-linguistic tests. Fatigue is common (Lindsay and Bone 2004). Only those considered to have sufficient stamina for assessment were recruited and rest opportunities were given during assessment. Time of test administration within the session did not appear to affect accuracy. Visual disturbances, such as diplopia and blurring are often reported (Lindsay and Bone 2004). Adequate vision for assessment was a referral criterion and was informally checked through discussion with participants and performance on the ABCD visual screening measures. The AIDS stimuli were enlarged as a facilitative measure. The functional disability rating scores (MBADLI) indicated that many participants had marked physical disability and dependence. Such disability was taken into account in ABCD test construction (Bayles and Tomoeda 1993), and all participants were able to provide a pointing response. In FC any recognisable attempt in keeping with level of physical disability was credited (for example, for the command 'Shrug your shoulders, pat your knee, then wiggle your fingers' full credit would be given for some shoulder movement, some approximation of a hand around the knee and some finger movement).

Depression is common in MS, may be the presenting symptom, and is especially prevalent in CP patients (Zakzanis 2000). Mood was not assessed in this study. Controlling for depression has not affected results in previous research (Beatty et al. 1989; Amato et al. 1995; Friend et al.1999) so it is unlikely that depression in the MS group would account for the current results, but this important symptom should be 
considered in future research. Also in view of potential effects on performance, relevant medication data should be included in future analyses.

The intelligibility assessment showed marked dysarthria in many of the MS group. Speech is the response medium for several ABCD measures, especially the four LEcon tests. In scoring the $\mathrm{ABCD}$, participants were not penalised for dysarthric features such as imprecise articulation, which in intelligibility assessment might result in indecipherable responses. In the LEcon tests there is a good degree of predictability of responses and all reasonable approximations to the target were credited (e.g. in $\mathrm{CN}$ stethoscope realised as [tદ?tદ?to], in OD [bãy wi ãm sãp de] accepted as bang with hammer, sharp, grey).

Where dysarthria affects rate of speaking, this may reduce the number of words generated in the timed GN test. The majority of respondents signalled completion well ahead of one minute and the level of discrimination from non-MS participants differed little from the non-timed $\mathrm{CN}$ test. Nevertheless, where motor speech is problematical, and probably effortful, participants may restrict their output in tests such as GN, OD and CD, thus negatively affecting scores. FC,CQ,WLR, RCW and RCS require no spoken response and in three of these no visual material is used. In all five tests, statistically significant differences from non-NS performance were present and effect sizes were all large (Cohen 1988). Thus while the possibility that functional disabilities, including motor speech, may affect performance on some subtests must be acknowledged, it is evident that cognitivelinguistic deficit is demonstrated in tasks where performance will not be influenced by dysarthria, physical disability, or visual impairment. 


\section{Episodic memory}

Story retelling tests (SRI and SRD) are administered at the start and end of ABCD testing. The SRD effect size was one of the largest of the $15 \mathrm{ABCD}$ measures, providing high MS and control group discrimination. The control group obtained similar scores on the two retellings, but MS group scores on SRD were significantly lower than on SRI (SRI mean 9.54, SRD mean 6.00). This is consistent with Zakzanis's (2000) evidence of a general pattern in MS of delayed recall being more impaired than immediate recall. SRI and SRD are particularly discriminating of the cortical dementia of Alzheimer's disease (Bayles and Tomoeda 1993). However the extent of difference between SRI and SRD in the current study does not equate with that in mild Alzheimer's disease subjects, for whom reported means are 7.3 and1.0 (Bayles and Tomoeda 1993). Word learning is assessed through three measures. First the participant attempts recall of 16 presented words (WLFR). Words not recalled are semantically cued, and the cued score is combined with WLFR (WLTR). Next the 16 stimuli plus 32 semantically related and unrelated words are orally presented for recognition of the initial stimulus set (WLR). The effect size for WLR was one of the smallest (though still large), while the largest ABCD effect size was for WLFR. MS participants recalled on average only 5 of the 16 words, versus 11 from control participants. All control participants achieved perfect WTRT scores (16), whereas the typical MS participant still failed to recall 2 or 3 items, though ability to respond to cues was clear (mean cued items: 7.96, SD 2.10). Control participants performed well on WLR with all but three having full scores (48). The average MS participant made five errors. Although recognition procedures did not result 
in performance equivalent to that of the control group, improvement over free recall was thus present, consistent with the analysis of Zakzanis (2000).

Whether episodic memory deficits in MS result from impairments at the stage of acquisition or retrieval has been debated. Zakzanis (2000) posits that people with MS initially register information into memory but do not retrieve it as well as control participants. Successful response to cueing and ability to recognise stimulus words and reject others, suggests that retrieval is especially vulnerable in MS. However in view of the significant differences in MS and control groups in both WLR and WLTR, as well as in WLFR, it may be argued that retrieval difficulty does not explain the entire episodic memory impairment, as forwarded by Gaudino et al. (2001).

\section{Language}

Word retrieval is a common focus for language assessment in MS. Impairments in both confrontation naming and generative naming (verbal fluency) have been reported repeatedly, both in language assessment (Lethlean and Murdoch 2000), and within broader neuropsychological testing. Zakzanis's (2000) meta-analysis found CP and RR MS types to be affected equally in confrontation naming. Generative naming was more affected, especially in CP type. Generative naming tasks are considered a sensitive measure of brain function (Gaudino et al. 2001), involving integration of various processes, including semantic memory and rapid information processing (Lethlean and Murdoch, 2000). In the present study, effect sizes differed little for GN and CN. This may be taken as indicative of a predominant word retrieval impairment of linguistic origin in 
the study population, as distinct from processing speed being the major factor. OD, with a larger effect size than GN, has similar requirements to GN, in that a range of associated words are required, though on a divergent rather than convergent dimension. CD was a particularly challenging test for the MS group, with an effect size almost as large as that of WRFR. Though word finding is an important component, CD evaluates knowledge of word meanings, by requiring verbalisation of the use and attributes of stimulus words. Murdoch and Lethlean (2000) similarly found tasks of word definition and association to be discriminative of MS.

Language comprehension has sometimes been excluded in MS studies, even in otherwise detailed assessments of language function. Some small studies have reported unimpaired comprehension (Wallace and Holmes 1993), but the results of some larger studies, including the detailed work of Murdoch and Lethlean (2000) and the meta-analysis of Zakazanis (2000), indicate comprehension deficit. This may be a later development in MS rather than an early feature (Amato et al. 1995) and is greater in CP than RR type (Zakzanis 2000). In the current study the LCcon effect size was smaller than that for LEcon, but nonetheless large. Although included within LCcon, repetition tasks are at times classed as memory assessments, especially where long stimuli are used, as in the $\mathrm{ABCD}$. Similarly memory is a component of FC, with the longest command 13 syllables. The extent to which difficulty in tests such as these is indicative of a linguistic processing or memory difficult is therefore unknown. 
Data on reading comprehension in MS is especially scant. Murdoch and Lethlean (2000) found relative preservation of reading ability. Kujala et al. (1996) noted a trend towards impaired reading comprehension in MS patients with mild cognitive decline. The low scores in both word and sentence level reading comprehension tests in the present study indicate that comprehension deficit in MS includes the written as well as the auditory modality. Given that some tests of comprehension in the $\mathrm{ABCD}$ minimise confounding effects of other potential disabilities, such as motor speech, physical and visual, the demonstration of statistically significant differences in these may carry particular weight.

\section{Mental Status}

In the $\mathrm{ABCD}$, mental status is assessed via MSt, which tests general knowledge and orientation to time, place and person. Even elderly people seldom make errors on MSt (Bayles and Tomoeda 1993). All control participants but only one third $(n=8)$ of the MS group achieved the full score. Some were unable to provide for example, the current year, their birth year or the month in which Christmas falls. Whether environment influences performance in this test was considered, as maintaining orientation may be more difficult when living in a care facility. Although the two lowest scorers lived in care facilities, interaction between environment and full versus not-full MSt score was not significant (Fisher exact test, $\mathrm{p}=1$ ). As a language based assessment, the ability to both understand the questions and formulate verbal responses is relevant to MSt. The focus is somewhat narrower than in measures such as the popular Mini Mental State Examination (Folstein et al. 1975) which includes memory, naming, imitation, carrying out commands and copying a drawing, all of which are included elsewhere in ABCD. Zakzanis (2000) 
reported MS discrimination on MMSE, with modest effect size. Wallace and Holmes (1993) found ABCD MSt to be unimpaired in four MS participants, whose speech was fully intelligible. This small group thus may not be comparable with the present investigation, in which, as with all other $\mathrm{ABCD}$ measures, a significant disadvantage relative to the control group was demonstrated in MSt.

\section{Extent of cognitive-linguistic deficit}

The extent of cognitive-linguistic deficit was greater than in many MS studies. This may be accounted for by the nature of the population studied. The CP type of MS has often been noted to be associated with greater level of disability than the RR type (Friend et al. 1999). The MS group characteristics were very similar to the CP population of the Zakzanis (2000) meta-analysis, in respect of age, education and functional disability, and a similar pattern of cognitive-linguistic disability might have been anticipated. However a higher level of discrimination between MS and control groups, as indicated by effect sizes, was noted in the present study. While there was commonality across some of the domains studied, such as verbal skill, the actual tests were not the same, and the ABCD tests may be more sensitive than some other measures. However an additional factor is that the MS participants in the current investigation had dysarthria and were known to SLT departments. The presence and extent of motor speech involvement is unknown in the studies evaluated by Zakzanis, and in some research speech impairment was an exclusion criterion. A tentative conclusion that may be reached from the high level of association between intelligibility and cognitive-linguistic measures is that those with $\mathrm{CP}$ MS who have impaired speech intelligibility are more vulnerable to cognitive-linguistic 
deficit than is the case for an unselected population. This is an important issue for speech and language therapists and other health professionals involved in the management of MS patients.

\section{Cognitive-linguistic deficit or dementia?}

Where cognitive impairment is present in MS, subcortical dementia, in which language and episodic memory are said to be preserved (Salmon and Filoteo, 2007), may be diagnosed. The evidence from this study argues against this diagnosis. Lethlean and Murdoch (2000) contend that cognitive-linguistic impairment in MS arises from both cortical and subcortical dysfunction, in that subcortical white matter lesions interrupt a circuit facilitating communication between cortical and subcortical structures. A cortical/subcortical boundary in classification of dementia may be artificial, given overlaps of pathology and symptom presentation (Kramer and Duffy 1996). Furthermore in view of the personality and behavioural features associated with dementia (MüllerSpahn 2003), the appropriateness of a diagnosis of dementia on the basis of cognitivelinguistic performance alone is questionable, and consideration should be given to broader based patient evaluation in future MS cognitive-linguistic research.

The performance profile observed in this MS population is best regarded within a broad context of cognitive-linguistic deficit. The interdependence of language and cognitive functions was referred to by Murdoch and Lethlean (2000). There is no language test which can be divorced from other cognitive domains. Attention and perception are fundamental to any testing, and the memory system is intrinsic to both language 
comprehension and expression. Tests of verbal memory and mental status utilise language, both comprehension and expression. Where language is used in assessment, attempts to divorce cognitive and linguistic function are artificial.

\section{Conclusions and clinical application}

Noting Zakzanis's (2000) caution that neurocognitive deficits require to be examined separately in subtypes of MS, the investigation was restricted to the CP type. The extent to which the results of this study apply to the RR pattern, in which significant speech problems are less prevalent (Yorkston et al. 2003), is an area for future research, as is the pattern of progression of cognitive-linguistic and intelligibility impairments over time. Clinical measures of cognitive-linguistic ability were utilised in this study. Extending the research to incorporate more functional measures such as Communication Activities of Daily Living - CADL-2 (Holland et al. 1999) would provide insight into the effects of cognitive-linguistic deficit on communication situations of everyday life. The inclusion of conversation analysis, in which the contributions of both MS patient and communication partner are evaluated, would allow the pattern of participant exchange and interaction to be viewed.

Many of the test deficits evident in this MS population are likely to be of everyday significance. Where someone cannot reliably answer basic questions of orientation, carry out simple commands, understand written words and recall factual information from 
narrative immediately, and more importantly after a period of an hour or so, day to independent living must be compromised, in health care settings, in work, education and social situations. Despite an average age of 47 , only three MS participants were in employment, either self-employed or working for a family member. The reason for this low employment rate is unknown, but influence of cognitive-linguistic impairment on employment might be considered in future research.

The results of this research indicate that speech and language therapists who deal with dysarthric patients who have the CP type of MS should be alert to the presence of cognitive-linguistic impairment and take account of this in their assessment, management and intervention, which may also embrace dysphagia. All health professionals who communicate with MS patients should be aware that auditory and reading comprehension, episodic memory and mental status may be impaired. Information, advice and practice materials may require to be adapted. Improved knowledge of the features of MS should also allow patients and their relatives to be better informed and prepared for possible symptom developments and to benefit from the empowerment that may result from informedness. 


\section{What this paper adds}

Both dysarthria and cognitive-linguistic deficit may be present in multiple sclerosis, but the association between these has not been investigated in clinical studies, nor has the pattern and extent of cognitive-linguistic loss in a dysarthric population been established.

This study of 24 patients with chronic progressive MS referred to speech and language therapy showed a strong association between levels of intelligibility and cognitivelinguistic ability. Relative to a control group, the MS group demonstrated a global loss of cognitive-linguistic skills. Cognitive-linguistic ability should be monitored in this population and considered in management. 
Table 1

\section{Participant data}

\begin{tabular}{|c|c|c|c|c|c|c|c|c|c|}
\hline Participant & Age & Gender & $\begin{array}{l}\text { Education } \\
\text { years }\end{array}$ & $\begin{array}{l}\text { Current or } \\
\text { last } \\
\text { employment }\end{array}$ & Participant & Age & Gender & $\begin{array}{l}\text { Education } \\
\text { years }\end{array}$ & $\begin{array}{l}\text { Current or last } \\
\text { employment }\end{array}$ \\
\hline MS1 & 23 & $\mathrm{~F}$ & 12 & Beautician & $\mathrm{C} 1$ & 21 & $\mathrm{~F}$ & 12 & Beauty therapist* \\
\hline MS2 & 31 & $\mathrm{~F}$ & 17 & $\begin{array}{l}\text { Engineering } \\
\text { Consultant* }\end{array}$ & $\mathrm{C} 2$ & 31 & $\mathrm{~F}$ & 17 & $\begin{array}{l}\text { Occupational } \\
\text { therapist* }\end{array}$ \\
\hline MS3 & 33 & $\mathrm{M}$ & 17 & $\begin{array}{l}\text { Accounts } \\
\text { Manager* }\end{array}$ & C3 & 37 & $\mathrm{M}$ & 17 & $\begin{array}{l}\text { University } \\
\text { administrator* }\end{array}$ \\
\hline MS4 & 33 & $\mathrm{~F}$ & 12 & $\begin{array}{l}\text { Hospital } \\
\text { Archivist }\end{array}$ & $\mathrm{C} 4$ & 33 & $\mathrm{~F}$ & 11 & Student \\
\hline MS5 & 37 & $\mathrm{~F}$ & 12 & Secretary & $\mathrm{C} 5$ & 36 & $\mathrm{~F}$ & 14 & Library assistant* \\
\hline MS6 & 38 & $\mathrm{~F}$ & 10 & $\begin{array}{l}\text { Shop } \\
\text { Assistant }\end{array}$ & C6 & 39 & $\mathrm{~F}$ & 11 & Shop Assistant* \\
\hline MS7 & 38 & $\mathrm{M}$ & 11 & PipeFitter & $\mathrm{C} 7$ & 38 & M & 12 & Police controller* \\
\hline MS8 & 41 & $\mathrm{~F}$ & 12 & $\begin{array}{l}\text { Shop } \\
\text { Manager }\end{array}$ & $\mathrm{C} 8$ & 42 & $\mathrm{~F}$ & 13 & Nursery nurse* \\
\hline MS9 & 42 & $\mathrm{M}$ & 17 & Metallurgist & C9 & 46 & $\mathrm{M}$ & 16 & Social worker* \\
\hline MS10 & 42 & $\mathrm{M}$ & 18 & $\begin{array}{l}\text { Bank } \\
\text { Director }\end{array}$ & $\mathrm{C} 10$ & 46 & $\mathrm{M}$ & 17 & Lecturer* \\
\hline MS11 & 44 & $\mathrm{M}$ & 11 & Joiner & C11 & 43 & $\mathrm{M}$ & 11 & Welder* \\
\hline MS12 & 45 & $\mathrm{~F}$ & 11 & Cashier & $\mathrm{C} 12$ & 42 & $\mathrm{~F}$ & 13 & Police controller* \\
\hline
\end{tabular}




\begin{tabular}{|c|c|c|c|c|c|c|c|c|c|}
\hline MS13 & 47 & $\mathrm{~F}$ & 12 & Telephonist & $\mathrm{C} 13$ & 45 & $\mathrm{~F}$ & 13 & Nursery nurse* \\
\hline MS14 & 47 & $\mathrm{M}$ & 12 & $\begin{array}{l}\text { Police } \\
\text { Officer }\end{array}$ & $\mathrm{C} 14$ & 46 & $\mathrm{M}$ & 11 & Mechanic* \\
\hline MS15 & 47 & $\mathrm{~F}$ & 15 & Nurse & $\mathrm{C} 15$ & 44 & $\mathrm{~F}$ & 14 & Nurse* \\
\hline MS16 & 48 & $\mathrm{M}$ & 17 & $\begin{array}{l}\text { Management } \\
\text { Consultant }\end{array}$ & $\mathrm{C} 16$ & 48 & $\mathrm{M}$ & 17 & Lecturer* \\
\hline MS17 & 51 & $\mathrm{~F}$ & 9 & $\begin{array}{l}\text { Poultry } \\
\text { Processor }\end{array}$ & $\mathrm{C} 17$ & 52 & $\mathrm{~F}$ & 11 & Secretary* \\
\hline MS18 & 53 & $\mathrm{~F}$ & 15 & Dental Nurse & $\mathrm{C} 18$ & 54 & $\mathrm{~F}$ & 15 & Secretary* \\
\hline MS19 & 58 & $\mathrm{M}$ & 11 & Bus Driver & C19 & 54 & $\mathrm{M}$ & 12 & Civil servant* \\
\hline MS20 & 58 & $\mathrm{M}$ & 18 & $\begin{array}{l}\text { Business } \\
\text { Analyst* }\end{array}$ & $\mathrm{C} 20$ & 59 & $\mathrm{M}$ & 19 & Computer analyst \\
\hline MS21 & 56 & $\mathrm{~F}$ & 14 & Nurse & $\mathrm{C} 21$ & 60 & $\mathrm{~F}$ & 14 & Administrator* \\
\hline MS22 & 64 & $\mathrm{~F}$ & 16 & Teacher & $\mathrm{C} 22$ & 62 & $\mathrm{~F}$ & 16 & Teacher* \\
\hline MS23 & 69 & $\mathrm{~F}$ & 10 & $\begin{array}{l}\text { Factory } \\
\text { Worker }\end{array}$ & $\mathrm{C} 23$ & 69 & $\mathrm{~F}$ & 11 & Housewife \\
\hline MS24 & 73 & $\mathrm{~F}$ & 11 & Housewife & $\mathrm{C} 24$ & 76 & $\mathrm{~F}$ & 12 & Housewife \\
\hline
\end{tabular}

* = currently employed 
Table 2

MS participant test scores, onset years and residence

\begin{tabular}{|c|c|c|c|c|c|}
\hline Participant & $\begin{array}{l}\text { ABCDOP } \\
\text { (20) } \\
\end{array}$ & $\begin{array}{l}\text { AIDS } \\
(220)\end{array}$ & $\begin{array}{l}\text { MBADLI } \\
(20)\end{array}$ & $\begin{array}{l}\text { Years since } \\
\text { MS onset }\end{array}$ & Residence \\
\hline MS1 & 11.15 & 160.00 & 18.00 & 4 & $\mathrm{H}$ \\
\hline MS2 & 19.60 & 216.00 & 11.00 & 2 & $\mathrm{H}$ \\
\hline MS3 & 16.20 & 203.00 & 18.00 & 12 & $\mathrm{H}$ \\
\hline MS4 & 13.85 & 199.00 & 10.00 & 6 & $\mathrm{H}$ \\
\hline MS5 & 12.25 & 35.00 & 0.00 & 11 & $\mathrm{CF}$ \\
\hline MS6 & 12.50 & 199.00 & 19.00 & 7 & $\mathrm{H}$ \\
\hline MS7 & 14.35 & 174.00 & 6.00 & 15 & $\mathrm{CF}$ \\
\hline MS8 & 15.15 & 196.00 & 19.00 & 6 & $\mathrm{H}$ \\
\hline MS9 & 17.20 & 210.00 & 10.00 & 13 & $\mathrm{H}$ \\
\hline MS10 & 15.05 & 199.00 & 9.00 & 8 & CF \\
\hline MS11 & 16.75 & 59.00 & 2.00 & 20 & $\mathrm{H}$ \\
\hline MS12 & 7.95 & 40.00 & 0.00 & 34 & $\mathrm{CF}$ \\
\hline MS13 & 13.25 & 35.00 & 4.00 & 33 & $\mathrm{H}$ \\
\hline MS14 & 15.25 & 59.00 & 0.00 & 9 & $\mathrm{H}$ \\
\hline MS15 & 18.50 & 217.00 & 5.00 & 14 & $\mathrm{H}$ \\
\hline MS16 & 18.45 & 180.00 & 7.00 & 10 & $\mathrm{H}$ \\
\hline MS17 & 15.50 & 203.00 & 20.00 & 2 & $\mathrm{H}$ \\
\hline MS18 & 9.35 & 29.00 & 0.00 & 7 & $\mathrm{CF}$ \\
\hline MS19 & 14.70 & 203.00 & 17.00 & 10 & $\mathrm{H}$ \\
\hline MS20 & 18.65 & 217.00 & 20.00 & 15 & $\mathrm{H}$ \\
\hline MS21 & 18.20 & 87.00 & 5.00 & 8 & $\mathrm{H}$ \\
\hline MS22 & 12.15 & 14.00 & 5.00 & 18 & $\mathrm{H}$ \\
\hline MS23 & 11.60 & 42.00 & 5.00 & 23 & $\mathrm{H}$ \\
\hline MS24 & 11.65 & 51.00 & 4.00 & 20 & $\mathrm{H}$ \\
\hline Mean (SD) & $\begin{array}{l}14.55 \\
(3.09)\end{array}$ & $\begin{array}{l}134.46 \\
(79.16)\end{array}$ & $8.92(7.14)$ & $12.79(8.48)$ & \\
\hline
\end{tabular}


ABCDOP: Overall profile score from 4 constructs of the Arizona Battery for Communication Disorders of Dementia (ABCD) (Bayles and Tomoeda 1993).

AIDS: Sentence intelligibility score from Assessment of Intelligibility of Dysarthric Speech (Yorkston and Beukelman 1984).

MBADLI: Total score from Modified Barthel Activities of Daily Living Index (Shah 1998)

$\mathrm{H}=$ home, $\mathrm{CF}=$ care facility 
Table 3

MS and control group data for ABCD overall performance and individual constructs

\begin{tabular}{|l|l|l|l|l|l|l|l|}
\hline Measure & $\begin{array}{l}\text { MS mean } \\
(\text { SD) }\end{array}$ & $\begin{array}{l}\text { control } \\
\text { mean } \\
\text { (SD) }\end{array}$ & $\mathbf{t} *$ & significance & $\begin{array}{l}\text { Mean } \\
\text { difference }\end{array}$ & $\begin{array}{l}\text { 95\% lower and upper } \\
\text { confidence interval }\end{array}$ & $\begin{array}{l}\text { effect size } \\
\text { (Cohen's d) }\end{array}$ \\
\hline $\begin{array}{l}\text { ABCDOP } \\
(\mathbf{2 0})\end{array}$ & $\begin{array}{l}14.55 \\
(3.09)\end{array}$ & $\begin{array}{l}19.30 \\
(0.40)\end{array}$ & -7.47 & .001 & -4.75 & $-6.04,-3.47$ & -2.16 \\
\hline MScon (5) & $\begin{array}{l}3.71 \\
(1.04)\end{array}$ & $5.00(0.00)$ & -6.08 & .001 & -1.29 & $-1.73,-.86$ & -1.75 \\
\hline EMcon (5) & $\begin{array}{l}3.79 \\
(0.54)\end{array}$ & $4.74(0.20)$ & -8.10 & .001 & -.95 & $-1.19,-.71$ & -2.33 \\
\hline LEcon (5) & $\begin{array}{l}3.39 \\
(0.82)\end{array}$ & $4.70(0.22)$ & -7.59 & .001 & -1.31 & $-1.67,-.96$ & -2.18 \\
\hline LCcon (5) & $\begin{array}{l}3.67 \\
(1.04)\end{array}$ & $4.86(0.17)$ & -5.52 & .001 & -1.20 & $-1.65,-.75$ & -1.61 \\
\hline
\end{tabular}

$*$ d.f. $=46$

Effect sizes all large $(\mathrm{d}=.8)$

ABCDOP: ABCD overall performance, MScon: Mental Status construct, EMcon: Episodic Memory construct, LEcon: Linguistic Expression contsruct, LCcon: Linguistic Comprehension construct 
Table 4

MS and control group performance data on ABCD tests

\begin{tabular}{|c|c|c|c|c|c|c|c|c|}
\hline test & construct & $\begin{array}{l}\text { MS mean } \\
\text { (SD) }\end{array}$ & $\begin{array}{l}\text { control } \\
\text { mean (SD) }\end{array}$ & $\mathbf{t}^{*}$ & significance & $\begin{array}{l}\text { mean } \\
\text { difference }\end{array}$ & $\begin{array}{l}95 \% \text { lower and } \\
\text { upper } \\
\text { confidence } \\
\text { interval }\end{array}$ & $\begin{array}{l}\text { effect size: } \\
\text { Cohen's d } \\
\text { (rank) }\end{array}$ \\
\hline WLFR (16) & EM & $5.54(2.28)$ & $11.29(2.39)$ & -8.53 & .001 & -5.75 & $-7.11,-4.39$ & $-2.46(1)$ \\
\hline $\mathrm{CD}(60)$ & $\mathrm{LE}$ & $\begin{array}{l}35.54 \\
(13.00)\end{array}$ & $57.46(3.12)$ & -8.03 & .001 & -21.92 & $-27.53,16.30$ & $-2.32(2)$ \\
\hline SRD (17) & EM & $6.00(4.61)$ & $14.00(1.93)$ & -7.85 & .001 & -8.00 & $-10.08,-5.92$ & $-2.26(3)$ \\
\hline OD & LE & $4.54(2.26)$ & $9.08(1.84)$ & -7.63 & .001 & -4.54 & $-5.74,-3.33$ & $-2.20(4)$ \\
\hline GN & LE & $7.46(3.51)$ & $13.54(2.95)$ & -6.50 & .001 & -6.08 & $-7.97,-4.20$ & $-1.88(5)$ \\
\hline CN (20) & LE & $14.88(4.12)$ & $19.46(0.83)$ & -5.34 & .001 & -4.58 & $-6.35,-2.82$ & $-1.54(6)$ \\
\hline SRI (17) & EM & $9.54(3.54)$ & $13.75(2.23)$ & -4.93 & .001 & -4.21 & $-5.94,-2.48$ & $-1.42(7)$ \\
\hline FC (9) & $\mathrm{LC}$ & $7.67(1.34)$ & $8.96(0.20)$ & -4.67 & .001 & -1.29 & $-1.86,-.72$ & $-1.35(8)$ \\
\hline WLTR (16) & EM & $13.50(2.75)$ & $16.00(0.00)$ & -4.45 & .001 & -2.50 & $-3.66,-1.34$ & $-1.29(9)$ \\
\hline $\mathrm{R}(75)$ & $\mathrm{LC}$ & $\begin{array}{l}59.29 \\
(12.91) \\
\end{array}$ & $71.29(4.69)$ & -4.28 & .001 & -12.00 & $-17.73,-6.27$ & $-1.24(10)$ \\
\hline MSt (13) & MS & $10.96(2.51)$ & $13.00(0.00)$ & -3.98 & .001 & -2.04 & $-3.10,-.98$ & $-1.15(11)$ \\
\hline $\operatorname{RCS}(7)$ & $\mathrm{LC}$ & $5.08(1.98)$ & $6.67(0.70)$ & -3.70 & .001 & -1.58 & $-2.50,-.71$ & $-1.07(12)$ \\
\hline WLR (48) & EM & $42.92(7.86)$ & $47.88(0.34)$ & -3.09 & .003 & -4.96 & $-8.28,-1.64$ & $-0.89(13)$ \\
\hline CQ (6) & $\mathrm{LC}$ & $5.04(1.52)$ & $5.96(0.20)$ & -2.93 & .004 & -.92 & $-1.56,-.27$ & $-0.85(14)$ \\
\hline RCW (8) & $\mathrm{LC}$ & $6.83(1.99)$ & $8.00(0.00)$ & -2.87 & .005 & -1.17 & $-2.01,-.31$ & $-0.83(15)$ \\
\hline
\end{tabular}

$*$ d.f. $=46$

Effect sizes all large $(\mathrm{d}=.8)$ 
Tests: WLFR: word learning - free recall, CD: concept definition, SRD: story retelling - delayed, OD: object description, GN: generative naming, CN: confrontation naming, SRI: story retelling - immediate, FC : following commands, WLTR: word learning total recall, R: repetition, MSt: mental status, RCS: reading comprehension - sentence, WLR: word learning - recognition, CQ: comparative questions, RCW: reading comprehension - word.

Constructs: MS: Mental Status, EM: Episodic Memory, LE: Linguistic Expression, LC: Linguistic Comprehension 
Figure 1

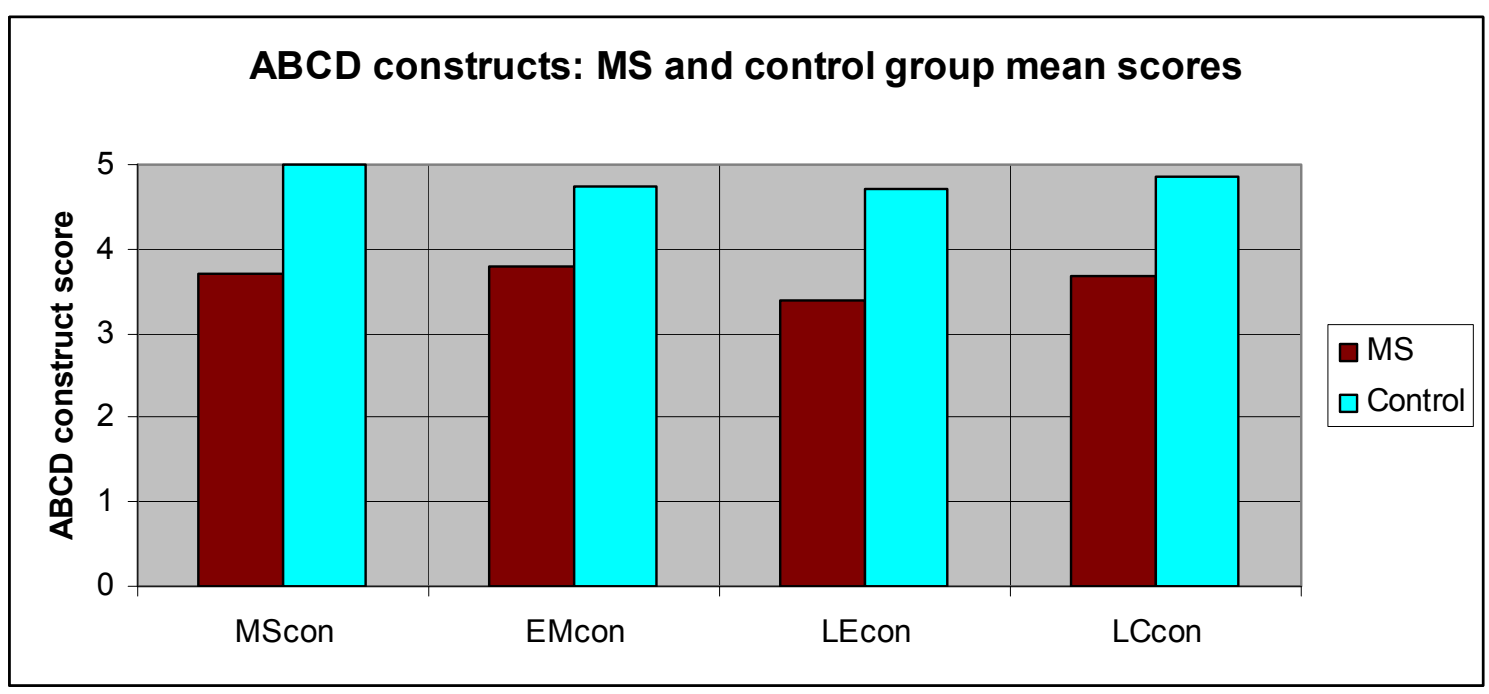

MScon: Mental Status construct

EMcon: Episodic Memory construct

LEcon: Linguistic Expression construct

LCcon: Linguistic Comprehension construct 


\section{References}

AMATO, M. P., PONZIANI, G., PRACUCCI, G., BRACCO., L., SIRACUSA, G. and AMADUCCI, L., 1995, Cognitive impairment in early-onset multiple sclerosis: Pattern, predictors, and impact on everyday life in a 4-year follow-up. Archives of Neurology, 52, $169-172$.

ARMSTRONG, L., BAYLES, K. A., BORTHWICK, S. E. and TOMOEDA, C. K., 1996, Use of the Arizona Battery for Communication Disorders of Dementia in the UK. European Journal of Disorders of Communication, 31, 171-180.

ARNOTT, W. L., JORDAN, F. M., MURDOCH, B. E. and LETHLEAN, J. B., 1997, Narrative discourse in multiple sclerosis: An investigation of conceptual structure. Aphasiology, 11, 969-991.

BAYLES, K. A. and TOMOEDA, C. K.,1993, Arizona Battery for Communication Disorders of Dementia. (Tucson: Canyonlands).

BEATTY, W. W., GOODKIN, D. E., MONSON, N. and BEATTY, P.A., 1989, Cognitive disturbances in patients with relapsing remitting multiple sclerosis. Archives of Neurology, 46, 1113-1119. 
CALACAGNO, P., RUOPPOLO, G., GRASSO, M. S., DE VINCENTIS, M. and PAOLUCCI, S., 2002, Dysphagia in multiple sclerosis - prevalence and prognostic factors. Acta Neurologica Scandinavica, 105, 40-43.

COHEN, J., 1988,. Statistical power analysis for the behavioral sciences (2nd ed.). (Hillsdale, NJ: Earlbaum).

DUFFY, J. R., 2005, Motor Speech Disorders: Substrates, Differential Diagnosis and Management, $2^{\text {nd }}$ edition. (St Louis: Elsevier Mosby).

FOLSTEIN, M. F., FOLSTEIN, S. E. and McHUGH, P. R., 1975, 'Mini-Mental State': A practical method for grading the cognitive state of patients for the clinician. Journal of Psychiatric Research, 12, 189-198.'

FRIEND, K. B., RABIN, B. M., GRONINGER, L., DELUTY, R. H., BEVER, C. and GRATTAN, L., 1999, Language functions in patients with multiple sclerosis. The Clinical Neuropsychologist, 13, 78-94.

GAUDINO, E. A., CHIARAVALLOTI, N. D., DELUCA, J. and DIAMOND, B. J., 2001, A comparison of memory performance in relapsing-remitting, primary progressive and secondary progressive, multiple sclerosis. Neuropsychiatry, Neuropsychology, and Behavioral Neurology, 14, 32- 44. 
GILROY, J., 2000, Basic Neurology, $3^{\text {rd }}$ edition (London: McGraw Hill).

HEATON, R. K., NELSON, L. M., THOMPSON, D. S., BURKS, J. S. and FRANKLIN, G. M., 1985, Neurological findings in relapsing remitting and chronic progressive multiple sclerosis. Journal of Consulting and Clinical Psychology, 53, 103-110.

HELM-ESTABROOKS, N., 2002 Cognition and aphasia: a discussion and study. Journal of Communication Disorders, 35, 171-186.

HOLlAND, A. L., FRATTALI, C. M. and FROMM, D., 1999, Communication Activities of Daily Living - CADL-2. (Austin Tx: Pro-Ed)

JENNEKENS-SCHINKEL, A., LANSER, J. B., VAN DER VELDE, E. A. and SANDERS, E. A., 1990, Performance of multiple sclerosis patients in tasks requiring language and visuoconstruction. Assessment of outpatients in quiescent disease stages. Journal of the Neurological Sciences, 95, 89-103.

KERR, A. W., HALL, H. K. and KOZUB, S. A., 2002, Doing Statistics with SPSS. (London: Sage Publications).

KLUGMAN, T. M. and ROSE, E., 2002, Perceptions of the impact of speech, language, swallowing, and hearing difficulties on quality of life of a group of South African persons with multiple sclerosis. Folia Phoniatrica et Logopaedica, 54, 201-221. 
KRAMER, J.H. and DUFFY, J.M., 1996 Aphasia, apraxia and agnosia in the diagnosis of dementia. Dementia, , $23-26$.

KUJALA, P., PORTIN, R. and RUUTIAINEN, J., 1996, Language functions in incipient cognitive decline in multiple sclerosis. Journal of the Neurological Sciences, 141, 79-86.

LAAKSO, K., BRUNNEGARD, K., HARTELIUS, L. and AHLSEN, E., 2000, Assessing high-level language in individuals with multiple sclerosis: A pilot study. Clinical Linguistics and Phonetics, 14, 329-349.

LETHLEAN, J. B. and MURDOCH, B. E., 1994, Naming in multiple sclerosis. Journal of Medical Speech-Language Pathology, 2, 43-56.

LETHLEAN, J. B. and MURDOCH, B. E., 2000, Subgroups of multiple sclerosis patients based on language dysfunction. In B. E. Murdoch and D. Theodoros (eds), Speech and Language Disorders in Multiple Sclerosis (London: Whurr).

LINDSAY, K. W. and BONE, I., 2005, Neurology and Neurosurgery Illustrated, $4^{\text {th }}$ edition (Edinburgh: Churchill Livingstone).

MACALLISTER, W. S., BELMAN, A. L., MILAZZO, M., WEISBROT, D. M., CHRISTODOULOU, C., SCHERL, W. F., PRESTON, T. E., CIANCIULLLI, C. and 
KRUPP, L. B., 2005, Cognitive functioning in children and adolescents in multiple sclerosis. Neurology, 64, 1422-1425.

MÜLLER-SPAHN, F., 2003, Behavioral disturbances in dementia. Dialogues in Clinical Neuroscience, 5, 49-59.

MURDOCH, B. E. and LETHLEAN, J. B., 2000, Language disorders in multiple sclerosis. In B. E. Murdoch and D. Theodoros (eds), Speech and Language Disorders in Multiple Sclerosis (London: Whurr).

MURDOCH, B. E. and THEODOROS, D., 2000, Speech and Language Disorders in Multiple Sclerosis (London: Whurr).

RAO, S. M., GARY, J. L., BERNARDIN, L. and UNVERZAGT, F., 1991, Cognitive dysfunction in multiple sclerosis. Neurology, 41, 685-691.

RON, M. A., CALLANAN, M. M. and WARRINGTON, E. K., 1991, Cognitive abnormalities in multiple sclerosis: A psychometric and MRI study. Psychological Medicine, 21, 59-68.

SALMON, D. P. and FILOTEO, J. V., 2007, Neuropsychology of cortical versus subcortical dementia syndromes. Seminars in Neurology, 27, 7-21. 
SHAH, S., 1998, Modified Barthel Index or Barthel Index (Expanded). In S. Salek. (Ed). Compendium of quality of life instruments Part II. (Chichester: Wiley and Sons).

THEODOROS, D. G. and WARD, E. C., 2000, Treatment of motor speech disorders in multiple sclerosis. . In B. E. Murdoch and D. Theodoros (eds), Speech and Language Disorders in Multiple Sclerosis (London: Whurr).

WALLACE, G. L. and HOLMES, S., 1993, Cognitive-linguistic assessment of individuals with multiple sclerosis. Archives of Physical Medicine Rehabilitation, 74, 637-643.

YORKSTON, K. M. and BEUKELMAN, D. R., 1984, Assessment of Intelligibility of Dysarthric Speech. (Austin, Tx: Pro-Ed).

YORKSTON, K. M., KLASNER, E. R. and SWANSON, K. M., 2001, Communication in context: A qualitative study of the experiences of individuals with multiple sclerosis. American Journal of Speech-Language Pathology, 10, 126-137.

YORKSTON, K. M., KLASNER, E. R., EHDE, D. M., GIBBONS, L. E., JOHNSON, K. and KRAFT, G., 2003, Characteristics of multiple sclerosis as a function of the severity of speech disorders. Journal of Medical Speech-Language Pathology, 11, 73-84. 
ZAKZANIS, K. K., 2000, Distinct neurocognitive profiles in multiple sclerosis subtypes. Archives of Clinical Neuropsychology, 15, 115-136. 


\section{Acknowledgements}

The research was supported by funding from the University of Strathclyde.

The authors also thank the participants and referring therapists, Helen Marshall, Ailsa

Cunningham, Janet Moar, Alexis Oates and Wendy Toner for their involvement in

assessment and transcription, Donnie Borland and Adam Wood for audio work, and Tom

Bryce for statistical advice. 